Portland State University

PDXScholar

$12-15-2021$

\title{
Virology: Mutagenizing the Proteolytic Cleavage Site in the Major Capsid Protein in SSV1
}

Thejanee Liyanaarachchi

Follow this and additional works at: https://pdxscholar.library.pdx.edu/honorstheses

Part of the Biology Commons, and the Virology Commons

Let us know how access to this document benefits you.

\section{Recommended Citation}

Liyanaarachchi, Thejanee, "Virology: Mutagenizing the Proteolytic Cleavage Site in the Major Capsid Protein in SSV1" (2021). University Honors Theses. Paper 1156.

https://doi.org/10.15760/honors.1188

This Thesis is brought to you for free and open access. It has been accepted for inclusion in University Honors Theses by an authorized administrator of PDXScholar. Please contact us if we can make this document more accessible: pdxscholar@pdx.edu. 
Virology: Mutagenizing the Proteolytic cleavage site in the major capsid protein in SSV1

by

Thejanee Liyanaarachchi

An Undergraduate honors thesis submitted in partial fulfillment of the requirements for the degree of Bachelor of Science

in

University Honors

and

Biology

Thesis Advisor

Dr. Kenneth Stedman

Portland State University

2021 


\section{Abstract}

SSV1, spindle-shaped virus 1, is an archaeal virus with a unique shape that belongs to the family Fuselloviridae and infects hyperthermophilic archaea that thrive at $80^{\circ} \mathrm{C}$ and $\mathrm{pH} 3$. SSV1 has two capsid proteins, VP1 and VP3, that presumably produce the lemon-shaped virion structure characteristic of fuselloviruses. The VP1 amino acid sequence is highly conserved among SSVs. Here, we investigate the importance of the proteolytic cleavage site at position 66 in VP1 by changing its glutamic acid to the other 19 amino acids. We have developed a new protocol for creating SSV1 mutants through HiFi Assembly (NEB) to increase the efficiency of mutagenesis and compile a library of SSV1 mutants. By optimizing this process -ensuring the original template is removed and that the total amount of DNA within the reaction lies below 0.2 picomoles-, we generated SSV1 mutants with the cleavage site of VP1 mutated to 16 other amino acids, demonstrating that HiFi Assembly can be used to successfully create a large number of mutations in a single reaction. We show that SSV1 mutant E66Q, with glutamine at the cleavage site, is viable and produces heterogeneous virion structure, while E66M, with methionine, produces virions similar to the wild-type. The characterization of the remaining mutants is ongoing.

\section{Introduction}

Viruses that infect Archaea are a diverse group of viruses that tend to have unique virion structures (Stedman et al. 2015, Rice et al. 2001). Many of the viruses that infect archaea are novel in that their predicted genes have no homology to any other genes from characterized viruses within any domain (Krupovic et al. 2014).

Fuselloviruses are a family of viruses found worldwide that infect hyperthermophilic and acidophilic Crenarchaea (Stedman et al. 2003, Prangishvili 2013). These viruses are characterized by a unique virion structure that resembles a spindle or lemon (Prangishvili 2013). The unique shape and ability of fuselloviruses to thrive in an extreme environment has intrigued many investigators. The most studied of fuselloviruses is SSV1, Sulfolobus spindle-shaped virus 1. SSV1 was the first fusellovirus to be discovered, from a hot spring in Beppu (Japan), and infects the hyperthermophilic archaea Saccharolobus solfataricus (previously known as Sulfolobus solfataricus) (Hiroyuki and Kurosawa 2018, Yeats et al. 1982, Martin et al. 1984). Sulfolobus and its viruses thrive at temperatures greater than $70^{\circ} \mathrm{C}$ and $\mathrm{pH} 3$ (Brock et al. 1972). SSV1 serves as a prototypical virus to better understand the genes and virion structure of fuselloviruses, and how it relates to propagation and thermostability (Iverson and Stedman 2012).

Much of the research on SSV1 has been on the virus' capsid proteins. SSV1 has two key capsid proteins associated with the spindle-shaped structure, virus protein 1 (VP1) and virus protein 3 (VP3) (Reiter et al. 1987). Another protein, virus protein 4 (VP4), is hypothesized to be the major tail protein (Quemin et al. 2015). VP1 and VP3 are highly conserved within all the characterized fuselloviruses, which implicates their 
importance for survival and propagation (Figure 1, Iverson et al. 2017a). Previous research has indicated that VP1 is essential while VP3 is non-essential, as infectious viruses lacking VP3 have been produced; however, the virions have an elongated shape (Iverson et al. 2017a). Genomic comparison has shown that VP1 and VP3 are paralogous and are derived from gene duplication as seen in Figure 2 (Iverson et al 2017b).

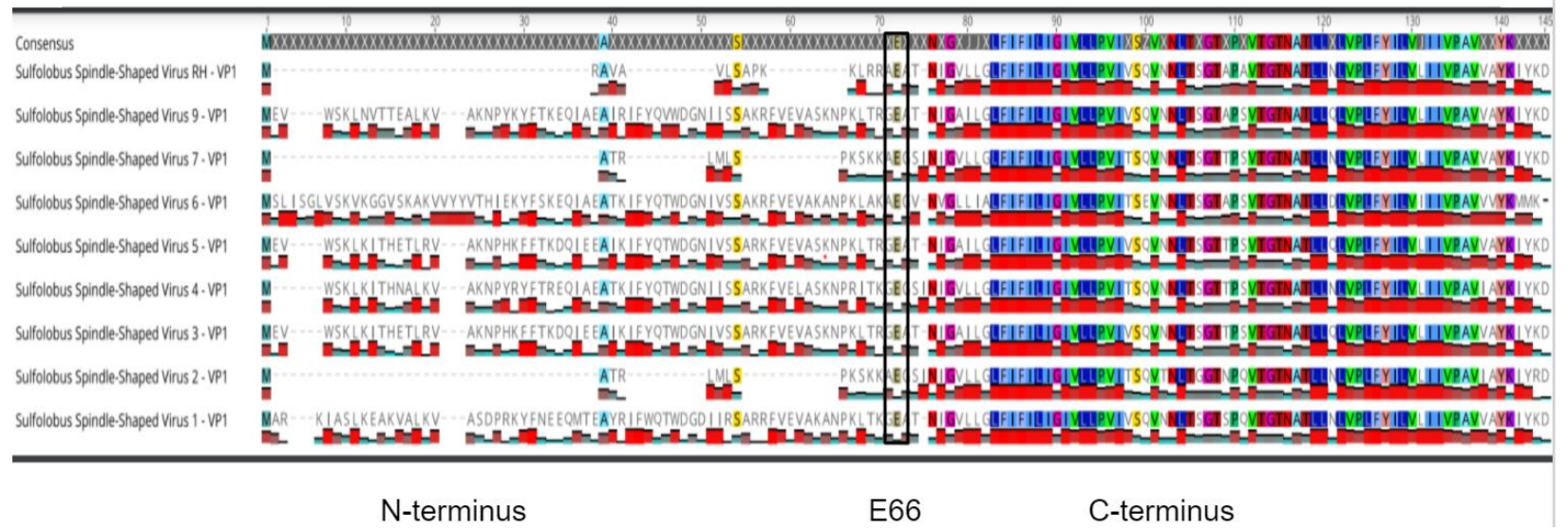

Figure 1: Sequence alignment of the SSV1 VP1 open reading frame conservation between SSV1 and 8 other SSV genomes. The cleavage site at glutamic acid 66 is boxed, conserved amino acids are shaded. Amino acid sequence alignment generated using Geneious.

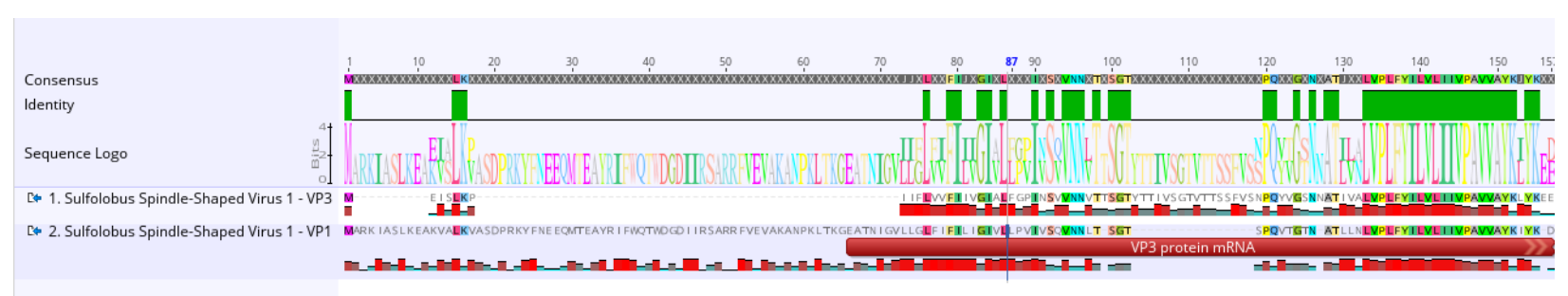

Figure 2: SSV1 VP1 and VP3 amino acid sequence alignment using Geneious using map to reference for Sanger sequencing results. VP1 and VP3 have many matching regions, shown in green, which indicates paralogy.

Studying VP1 is pertinent due to its conserved nature within fuselloviruses (Figure 1). VP1 has a cleavage site at its amino acid position 66. Previous research has indicated that the N-terminus of VP1 -up to residue E66- is essential for the virus since viruses with both complete and partial deletions of the $\mathrm{N}$-terminus were not infectious (Iverson et al. 2017b). However, the N-terminus or the entire VP1 can be interchanged between different SSVs without compromising infectivity (Iverson et al. 2017b). Previous results have shown that VP1 is proteolytically modified after translation (Reiter et al. 1987). The processing takes place at the glutamic acid at position 66 (E66) and may be important for the maturation of the virion (Quemin et al. 
2015). Mutations to glutamine or alanine in position 66 result in viable virus but with structural abnormalities (Iverson et al. 2017b). The role of the proteolytic cleavage site in SSV1 virion maturation remains unknown. The SSV1 virion structure is of great interest because it is able to withstand extreme temperature $\left(80^{\circ} \mathrm{C}\right)$ and acidity $(\mathrm{pH} 3)$, while maintaining protein tertiary and quaternary structures (Iverson and Stedman 2012). The study of the two capsid proteins of SSV1, VP1 and VP3, enables a better understanding of these unique biological structures and shed light on biological molecules' ability to interact in extreme environments.

The primary goal was to generate SSV1 viruses containing VP1 mutants with its glutamic acid changed to all other 19 amino acids. In order to generate these mutants and for future research, we describe here the development of a robust protocol to produce point mutations. Previously, SSV1 has been mutagenized using long-inverse PCR with mutagenic primers (Iverson et al. 2017a and b); however, this method is inefficient, as it can only produce one mutant at a time and is very time consuming. HiFi Assembly is an adaptation of the Gibson Assembly that utilizes proteins with DNA polymerase, exonuclease and ligase activities. Briefly, overlapping DNA fragments are produced, and overhangs that are complementary to the other adjoining fragments are produced and assembled by the enzymes present in the HiFi Assembly mixture (Figure 3; Sultan et al. 2020). Here, we describe the generation of SSV1 mutants with the cleavage site of VP1 mutated to 16 other amino acids using a mutagenic oligonucleotide with ambiguous bases, demonstrating that HiFi Assembly can be used to successfully create a large number of mutations using a single reaction.

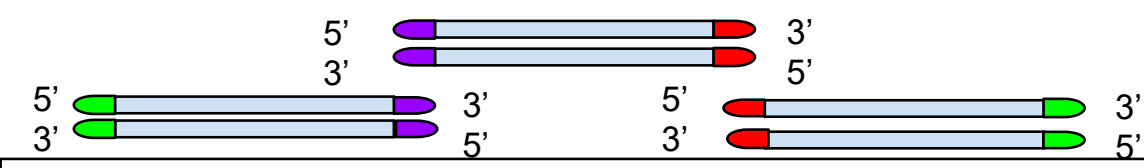

Exonuclease activity

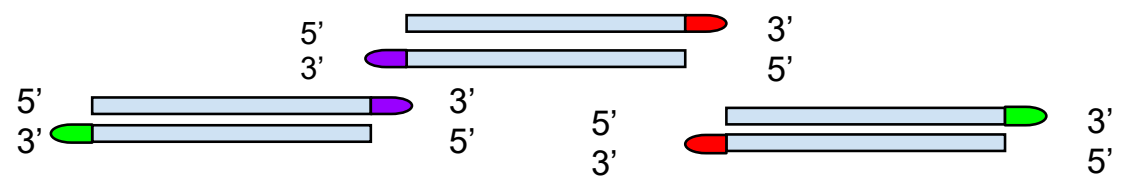

\section{Ligation activity}

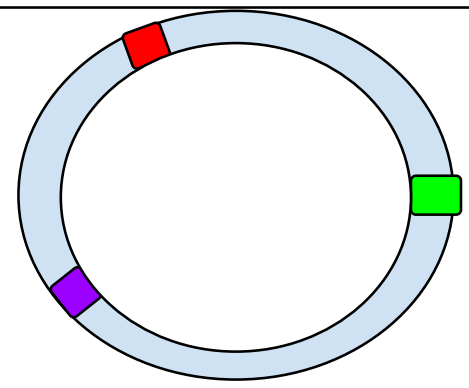

Figure 3: HiFi Assembly process overview. The different colors, red, green, and purple, represent the overlapping overhangs. 


\section{Methods and Materials}

PCR amplification

A plasmid containing the wild-type SSV1 genome, an E. coli origin of replication, and kanamycin antibiotic resistance, the EAl283 vector (Iverson et al. 2017a), was amplified in three overlapping pieces with Q5 DNA polymerase (NEB). Fragment 1 was generated with primers VP1 HiFi E66 F and SSV1 Int Bind, fragment 2 with primers SSV1 VP1 Nterm R and SSV UNV3 F, and fragment 3 with primers UNV SSV\#3 comp and SSV1 Int Bind New (all oligonucleotides used were purchased from IDT and are shown in Table 1 and Figure 4). The PCR conditions are shown in Table 2. These overlapping fragments leave a gap in the sixty-sixth position in VP1 (Figure 4). The correct length of the fragments was confirmed by agarose gel electrophoresis (Sambrook et al. 2006).

For mutating VP1 E66 to methionine, a mutagenic primer within the PCR was used instead of the mutagenic oligonucleotide. In this procedure the VP1 HiFi E66 F in fragment 1 was replaced with E66M F primer and the SSV1 VP1 Nterm R primer of fragment 2 was replaced with E66M R (Table 1). Fragment 3 is kept under the same conditions. To ensure the annealing of the two mutagenic primers, the annealing temperature was lowered from $63^{\circ} \mathrm{C}$ to $60^{\circ} \mathrm{C}$. The methionine Fragments, 1 and 2 , contain the mutations and overhangs. From this point onwards fragments $1,2,3$, were treated with the exact same conditions for the HiFi assembly.

Dpnl digestion

Once the fragments were determined to be the expected size using gel electrophoresis, a Dpnl treatment was used to remove the original template. Each DNA fragment was treated with $1 \mu \mathrm{l}$ or unit of Dpnl from NEB, an enzyme that cuts methylated DNA, thereby removing the original template. The solution was left overnight at $37^{\circ} \mathrm{C}$. Afterwards the reaction was placed into an $80^{\circ} \mathrm{C}$ bead bath for the enzyme to become denatured. Then each fragment was purified using the NEB Monarch PCR and DNA Cleanup Kit, and the concentration of the DNA (nanogram/ $\mu$ l) was determined using a nanodrop spectrophotometer (Thermo).

\section{HiFi Assembly}

A mutagenic oligonucleotide mixture with the degenerate sequence NNK (to generate codons for all possible amino acids at the sixty-sixth position; Table 1) was mixed with the three amplified linear DNA fragments for HiFi Assembly at a total concentration of $<0.2$ picomoles. The assembly of the plasmid - allowed by the overlap between the DNA fragments - was performed using a HiFi Assembly kit (NEB; Figure 3) following the manufacturer's guidelines.

Table 1: Primers used for each PCR amplification reaction. 


\begin{tabular}{|c|c|c|}
\hline Use & Forward Primer with Sequence & Reverse Primer \\
\hline Fragment 1 & $\begin{array}{l}\text { VP1 HiFi E66F: } \\
\text { 5'-GCAACCAACATAGGCGTA-3' }\end{array}$ & $\begin{array}{l}\text { SSV1 Int Bind: } \\
\text { 5- } \\
\text { GCGGATAAAATAT } \\
\text { TGAAAGCG-3 }\end{array}$ \\
\hline Fragment 2 & $\begin{array}{l}\text { SSV UNV3 F: } \\
\text { 5-CAATCGCCATAGGCTACGG-3 }\end{array}$ & $\begin{array}{l}\text { SSV1 VP1 Nterm R: } \\
\text { 5- } \\
\text { ACCTTTTGTGAGC } \\
\text { TTGGG-3 }\end{array}$ \\
\hline Fragment 3 & $\begin{array}{l}\text { SSV1 Int Bing new: } \\
\text { 5-CGCTTTCAATATTTTATCCGC-3 }\end{array}$ & $\begin{array}{l}\text { UNV SSV\#3 comp: } \\
\text { 5- } \\
\text { CCGTAGCCTATGG } \\
\text { CGATTG-3 }\end{array}$ \\
\hline $\begin{array}{l}\text { Mutagenic } \\
\text { oligonucleo } \\
\text { tide }\end{array}$ & $\begin{array}{l}\text { 5- } \\
\text { AAGGCAAACCCCAAGCTCACAAAAGGTNNKG } \\
\text { CAACCAACATAGGCGTATTGTTGGGC-3 * }\end{array}$ & \\
\hline $\begin{array}{l}\text { Methionine } \\
\text { Fragment } \\
1\end{array}$ & $\begin{array}{l}\text { E66M-F: } \\
\text { 5-C ACA AAA GGT ATG GCA ACC AAC A-3 * }\end{array}$ & $\begin{array}{l}\text { SSV1 Int Bind: } \\
\text { 5- } \\
\text { GCGGATAAAATAT } \\
\text { TGAAAGCG-3 }\end{array}$ \\
\hline $\begin{array}{l}\text { Methionine } \\
\text { Fragment } 2\end{array}$ & $\begin{array}{l}\text { SSV UNV3 F: } \\
\text { 5-CAATCGCCATAGGCTACGG-3 }\end{array}$ & $\begin{array}{l}\text { E66M-R: } \\
\text { 5-G TGT TTT CCA } \\
\text { TAC CGT TGG TTG } \\
\text { T-3 * }\end{array}$ \\
\hline $\begin{array}{l}\text { Colony/sup } \\
\text { ernatant } \\
\text { PCR }\end{array}$ & $\begin{array}{l}\text { VP1_F: } \\
\text { 5-TTGGCAAGAAAGATAGCCTC-3 }\end{array}$ & $\begin{array}{l}\text { SSV1 T2R: } \\
\text { 5- } \\
\text { CGTGCTTTATCGC } \\
\text { CTTATCG-3 }\end{array}$ \\
\hline $\begin{array}{l}\text { Assembly } \\
\text { Confirmatio } \\
\text { n PCR }\end{array}$ & $\begin{array}{l}\text { LIPCR_B251 F: } \\
\text { 5-ATTGACGACGTAACAAGATAG-3 }\end{array}$ & $\begin{array}{l}\text { F92 LIPCR R: } \\
\text { 5- } \\
\text { ATAGCATGGCTAG }\end{array}$ \\
\hline
\end{tabular}




\begin{tabular}{|l|l|l|}
\hline & & AATACAAGG-3 \\
\hline
\end{tabular}

* The bolded nucleotides represent changes in the E66 position in VP1 from the wildtype GAA

Assembly Confirmation

To ensure that the plasmid assembled with the different fragments in the proper orientation, another PCR was used, with primers F92 LIPCR R and LIPCR B251 F (Table 1). Alternatively, restriction endonuclease digestion of the purified plasmid with the enzymes Ncol or Xmal was used followed by agarose gel electrophoresis (Figure $5)$.

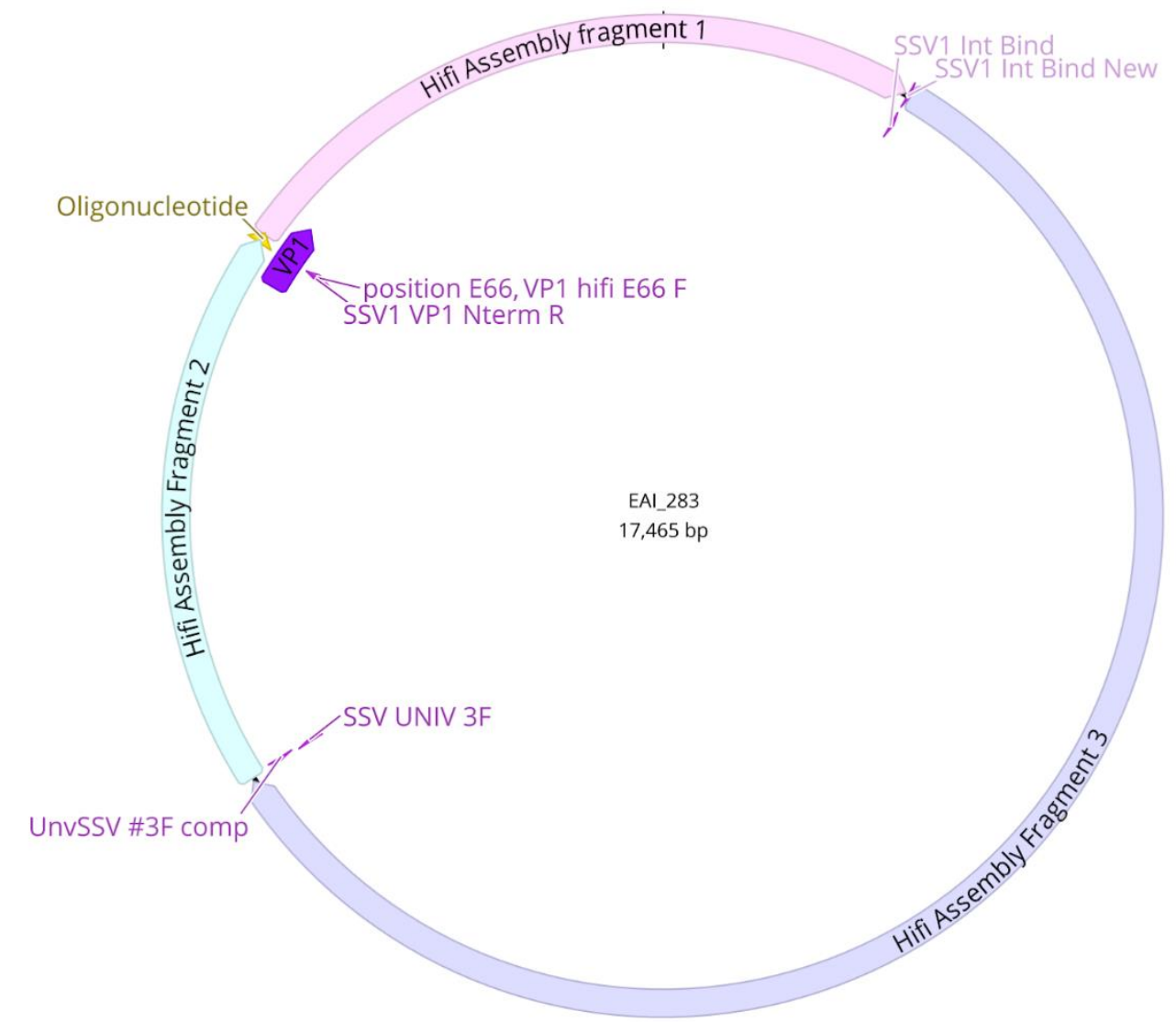

Figure 4: Representation of amplified fragments 1, 2 and 3 used for HiFi Assembly with respect to VP1 in the shuttle vector EAl283 and the location of primers used for amplification.

Transformation

The HiFi reaction products were transformed into competent pir+ E. coli cells (Epicentre Biotechnologies) using heat-shock (Iverson et al. 2017a). The transformed $E$. 
coli were grown for $2-3$ days at $37^{\circ} \mathrm{C}$ on agar plates with LB and 100 micrograms $/ \mathrm{mL}$ of kanamycin (antibiotic) (Sambrook et al. 2006).

\section{Colony PCR}

Individual colonies observed on the LB plate after incubation were treated as independent mutants. Each colony was collected using a pipette tip and resuspended in $50 \mu \mathrm{l}$ of LB and Kanamycin broth. One $\mu \mathrm{l}$ of the resuspended cells was used as a PCR template. A PCR with the primers VP1_F and SSV1 T2R was performed using Taq 2x Master Mix (NEB) to amplify the region containing VP1 and VP3 (Tables $1 \& 2$ ). The PCR products were screened using gel electrophoresis, and the amplicons with the expected size $(0.8 \mathrm{~Kb})$ were purified with Monarch PCR and DNA Cleanup Kit (NEB) and sequenced.

Table 2: Thermocycling conditions for the PCR reactions.

\begin{tabular}{|l|l|l|l|}
\hline & $\begin{array}{l}\text { Q5 PCR } \\
\text { temperature and } \\
\text { time }\end{array}$ & $\begin{array}{l}\text { Q5 Methionine PCR } \\
\text { Temperatures and } \\
\text { time }\end{array}$ & $\begin{array}{l}\text { Colony/Supernatant PCR } \\
\text { temperature and time }\end{array}$ \\
\hline Initial & $98^{\circ} \mathrm{C}$ for $30 \mathrm{~s}$ & $98^{\circ} \mathrm{C}$ for $30 \mathrm{~s}$ & $95^{\circ} \mathrm{C}$ for $30 \mathrm{~s}$ \\
\hline Denaturing & $98^{\circ} \mathrm{C}$ for $10 \mathrm{~s}$ & $98^{\circ} \mathrm{C}$ for $10 \mathrm{~s}$ & $95^{\circ} \mathrm{C}$ for $10 \mathrm{~s}$ \\
\hline Annealing & $63^{\circ} \mathrm{C}$ for $30 \mathrm{~s}$ & $60^{\circ} \mathrm{C}$ for $30 \mathrm{~s}$ & $49^{\circ} \mathrm{C}$ for $30 \mathrm{~s}$ \\
\hline Elongation & $\begin{array}{l}72^{\circ} \mathrm{C} \text { for } 8: 30 \\
\min \end{array}$ & $72^{\circ} \mathrm{C}$ for $8: 30 \mathrm{~min}$ & $68^{\circ} \mathrm{C}$ for $1 \mathrm{~min}$ \\
\hline $\begin{array}{l}\text { Final } \\
\text { Elongation }\end{array}$ & $72^{\circ} \mathrm{C} 5 \mathrm{~min}$ & $72^{\circ} \mathrm{C} 5$ min & $68^{\circ} \mathrm{C}$ for $5 \mathrm{~min}$ \\
\hline Cooling & $12^{\circ} \mathrm{C}$ & $12^{\circ} \mathrm{C}$ & $12^{\circ} \mathrm{C}$ \\
\hline
\end{tabular}




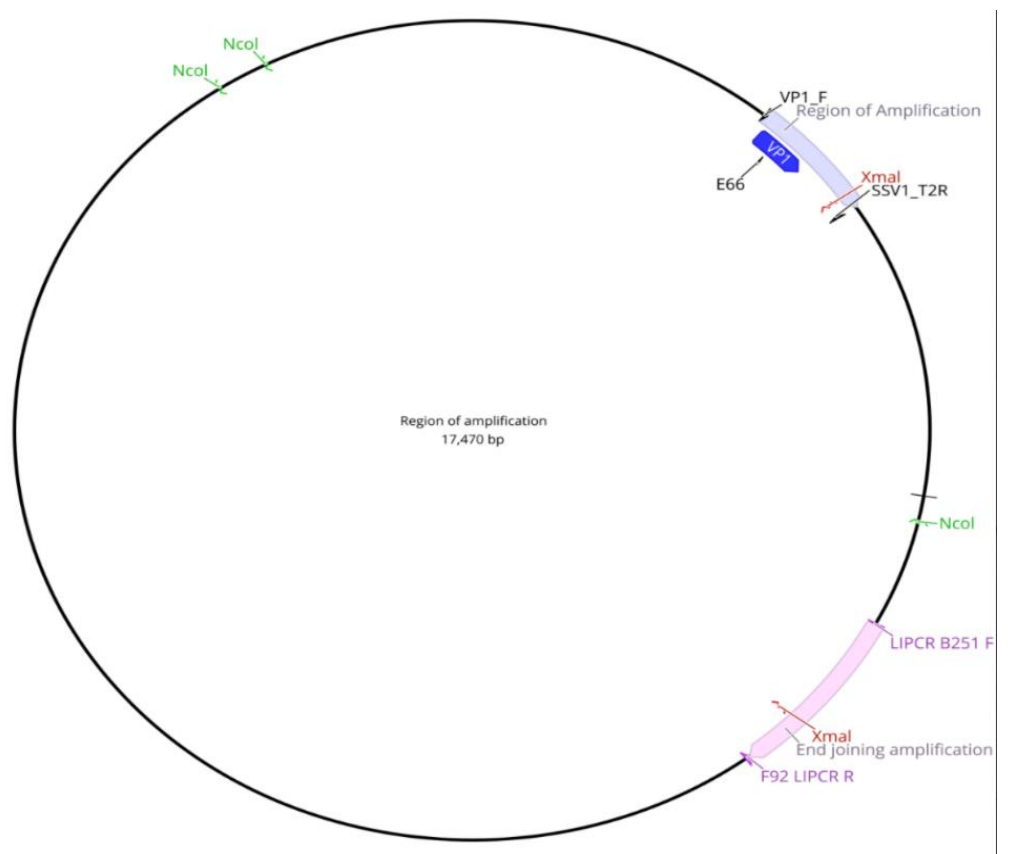

Figure 5: The vector, EAI283, shows the primers and the region of amplification for the supernatant and colony PCR, seen in blue, with respect to VP1 and E66. The pink is the region of amplification used in the assembly confirmation PCR. The red, Xmal, and green, Ncol, are the locations that the two restriction endonucleases cut to check for proper orientation of the fragments after assembly.

Sequencing and analysis

Purified amplicons were mixed with a single primer, either VP1_F or SSV1 T2R, and sequenced commercially (using Sanger sequencing; Eurofins Genomics). The resulting chromatograms were mapped to EAI283 with UGene version 36 (http://ugene.net) to determine the amino acid changes produced in VP1 at position E66.

\section{Electroporation}

Each colony containing a confirmed mutation in position 66 of VP1, was grown overnight in $5 \mathrm{~mL}$ of LB and Kanamycin. The plasmids were isolated using a Miniprep DNA extraction kit (NEB). 200-500 ng of the mutated plasmids were electroporated into concentrated Saccarolobus solfataricus strain S441 washed in sucrose solution using a BioRad GenePulser via $1.5 \mathrm{kV}$ electrical field, 400 ohms, 25 microFaraday with a time constant of about 9 milliseconds, to recover infectious viruses (Iverson et al. 2017a).

\section{Culturing of Saccharolobus (Sulfolobus) solfataricus}

The electroporated samples were added to $1 \mathrm{~mL}$ heated YS media (Iverson et al. 2017a) for one hour before being transferred to an Erlenmeyer flask containing $50 \mathrm{~mL}$ of heated YS media. Then the flasks were transferred to a $80^{\circ} \mathrm{C}$ shaking polyethylene glycol 400 bath. The cultures were incubated for 2-5 days before analysis. 


\section{Supernatant PCR}

A $1 \mathrm{~mL}$ sample of the culture was taken from the flasks after $2-5$ days. The aliquot was centrifuged at $3260 \mathrm{xg}$ for $15 \mathrm{~min}$, to separate the virions in the supernatant from cells in the pellet. To determine infectivity of SSV1 mutants, this supernatant was used as a template for a PCR performed with Taq 2X Master Mix (NEB) and the primers VP1_F and SSV1 T2R (Supernatant PCR; Tables $1 \& 2$ ). The amount of supernatant was doubled to $2 \mu$ lo yield sufficient product that could be sequenced when necessary. Thermocycling conditions were the same as for colony PCR (Table 2).

\section{Halo Assay}

To further determine the infectivity of each of the mutants, electroporated cultures were tested for their ability to cause host cell growth inhibition in a test called a halo assay (Iverson and Stedman 2012). S441, uninfected Saccharolobus (Sulfolobus) solfataricus strain, stocks were grown in $7 \mathrm{~mL}$ of YS media and let grow to an OD of 0.6. Then the cells are centrifuged at $3260 \mathrm{xg}$ for $15-20 \mathrm{~min}$. Then the supernatant is decanted, and the pellet resuspended in $0.5 \mathrm{~mL}$ of $Y S$ media. $3 \mathrm{~mL}$ of soft layer $(0.2 \%$ Gelrite in YS) is mixed with the $0.5 \mathrm{~mL}$ of cell concentrate and poured onto heated $Y S$ plates. The soft layer is left to harden on a leveled surface for 20-30 min. Afterwards, 5 $\mu \mathrm{l}$ of the confirmed electroporated mutants are spotted on the plate and left to dry for 15 min. After a $2-5$ days incubation period at $80^{\circ} \mathrm{C}$, a halo in the lawn is observed if an infectious mutant inhibits the growth of the lawn cells.

\section{Transmission Electron Microscopy}

The virions of the infectious mutant viruses were examined by transmission electron microscopy (FEI Tecnai F-20) to see whether abnormalities were present in the structure of the capsid and if virions were being produced. Virions were prepared by taking a $50 \mathrm{~mL}$ culture and centrifuging the culture at $3260 \mathrm{xg}$ for $15-25 \mathrm{~min}$. Then the supernatant was taken and the sample was concentrated further using a Vivaspin 6 $6 \mathrm{~mL}$ centrifugal concentrator to between 100 and $200 \mu \mathrm{l}$. Then $3 \mu \mathrm{l}$ of the concentrated sample was added to a formar-carbon coated copper grid (Ted Pella), stained three times with $2 \%$ uranyl acetate for 2 minutes, and washed with distilled water. Grids were air dried and imaged in a Tecnai F-20 transmission electron microscope.

\section{Results}

The aim of this study was to construct mutants with all other 19 amino acids encoded at the E66 position of VP1 in SSV1. Our attempts to conduct a long-inverse PCR (Iverson et al. 2017b, Clore and Stedman 2006) leaving only a gap for the mutagenic oligonucleotide using the primers VP1 HiFi E66 F and SSV1 VP1 Nterm R was not successful (data not shown). Thus, there was a need to establish a different cloning strategy. To introduce the mutation into the SSV1 shuttle vector, the SSV1 
shuttle vector (EAI283) was amplified in three different fragments because of its large size (Figure 4). A mutagenic oligonucleotide bridge was designed with an NNK sequence and an overlapping region on either side to allow for the region to be joined by the enzymes in the HiFi Assembly kit (Figures 3 and 4; NEB). HiFi Assembly was used to assemble three PCR-generated fragments (Figure 4) with the bridging degenerate oligonucleotide that mutated the putative E66 cleavage site of SSV1's VP1 (Figure 4). The three fragments migrated as expected relative to size standards in agarose gel electrophoresis: fragment 1 being $\sim 3 \mathrm{~Kb}$, fragment 2 being $\sim 4 \mathrm{~kb}$, and fragment 3 being $\sim 10 \mathrm{~Kb}$ (Figure 6). To produce the methionine substitution, due to the low representation of this amino acid in the genetic code, fragments 1 and 2 were constructed using methionine mutagenic primers and no bridging degenerate oligonucleotide. The sizes of the fragments were approximately the same (Figure 6).
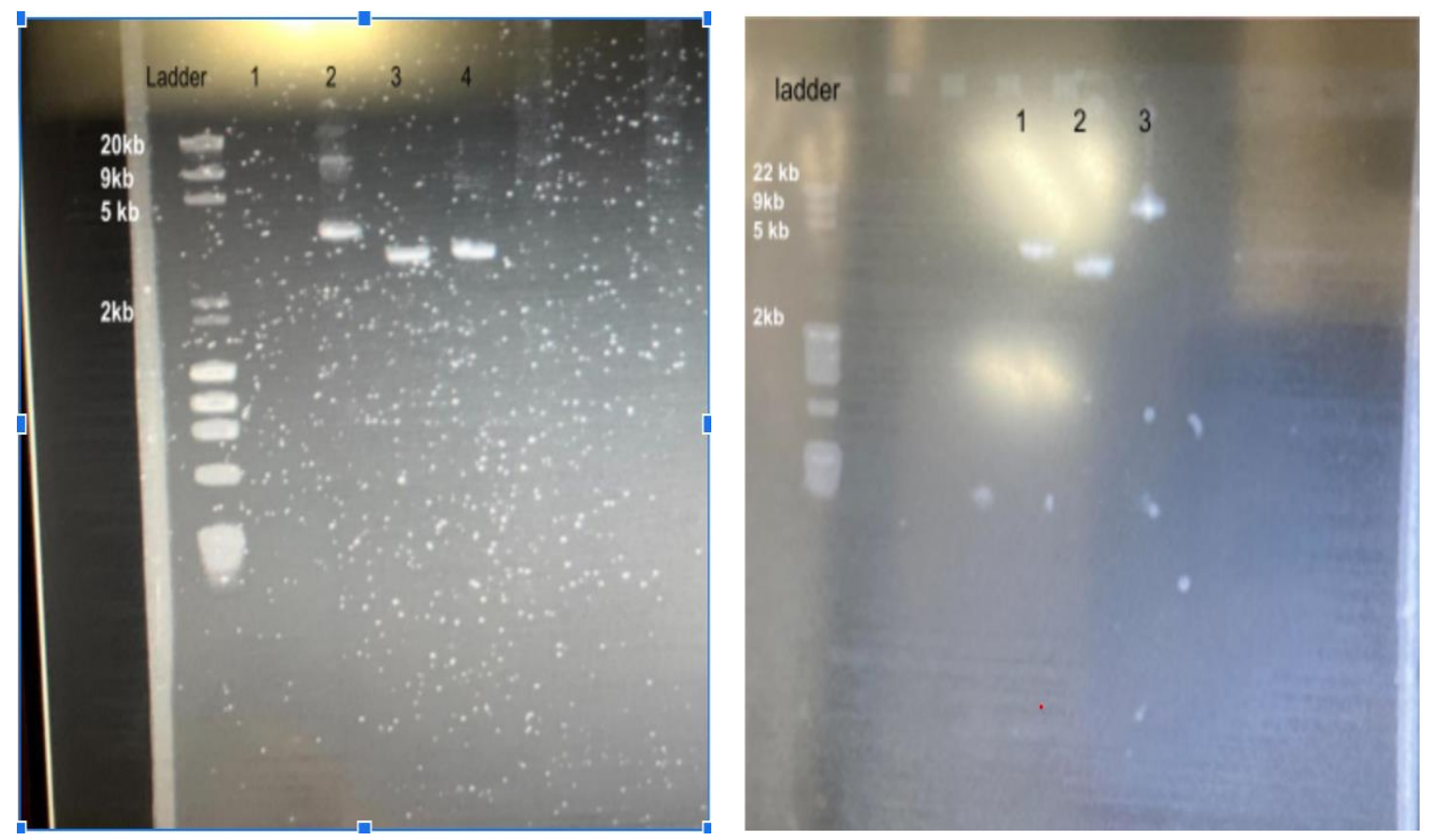

Figure 6: Agarose gel electrophoresis of PCR products for HiFi Assembly: A) Ladder: Broad range ladder (NEB) with sizes labeled; Lane 1, empty; Lane 2, fragment 3; Lane 3, fragment 1; Lane 4, fragment 2. B) DNA fragments produced by PCR for the methionine mutant. Ladder, Broad range ladder (NEB) with sizes labeled; Lane 1, fragment 2; Lane 2, fragment 1; Lane 3, fragment 3.

After the HiFi Assembly was completed, the SSV1-containing vectors were transformed into pir+ E.coli. These transformed E.coli were placed on a plate and left to grow for 2-3 days (Figure 7). Then, individual colonies were selected and underwent colony PCR and the PCR products separated by gel electrophoresis. The colonies that generated a PCR product of the approximate size of $0.8 \mathrm{kbp}$ were sequenced by Sanger sequencing. Three separate attempts at conducting HiFi Assembly were completed to 
optimize the outcome. The first round of HiFi Assembly resulted in about $60 \%$ of the screened mutants having the wild-type GAA codon with only two confirmed mutants (Figure 8 and Table 3). In the second round, 90\% of colonies contained a consistent deletion mutation presumably due to a small, repeated region in the virus' genome between VP1 positions 64 and 99, where there's a 7nt direct repeat (CTCACAA) (Figure 9 and Table 3). The one successful E66 substitution is not depicted in Figure 9. The third attempt was the most successful, with all screened colonies containing mutants. Through the third round of the HiFi assembly, 13 mutants containing new amino acids at the putative cleavage site were produced, as confirmed through Sanger sequencing (Figure 10 and Table 3). However, there were many clones containing the same codons that were found within the last round of assemblies, as seen in Table 3.

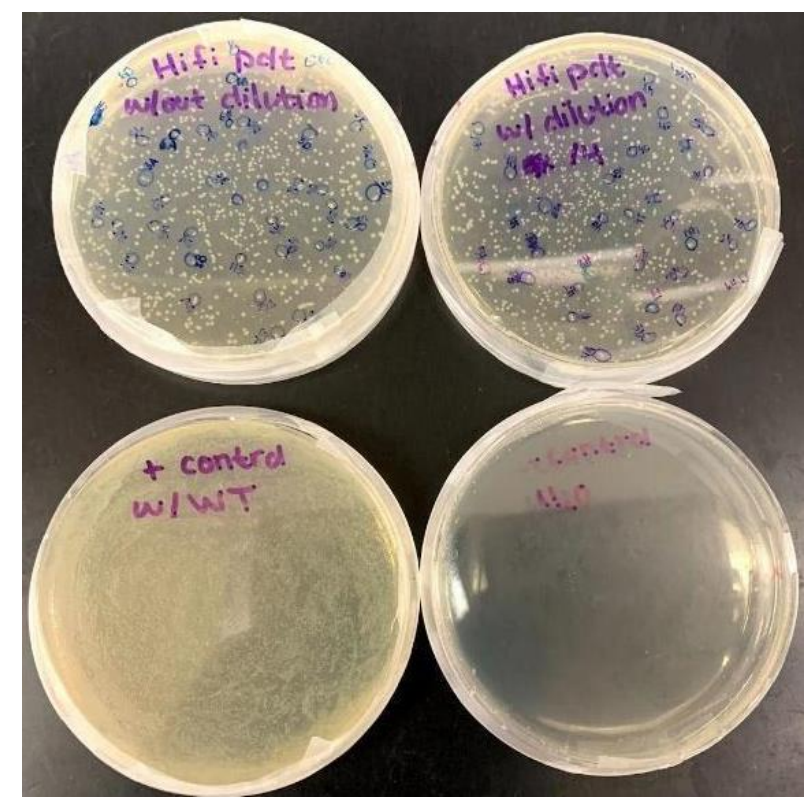

Figure 7: Representative growth of E.coli transformants and controls. pir+ E.coli was transformed with the indicated sample and plated on LB plus kanamycin agar plates and grown for $2-3$ days at $37^{\circ} \mathrm{C}$. The top two plates were transformed with $\mathrm{HiFi}$ Assembly mixture, left undiluted and right diluted $4 x$ with water. The bottom plates are controls. Left was transformed with EAI283 (positive control). Right was transformed with water (negative control). Colonies chosen for analysis are circled in blue.

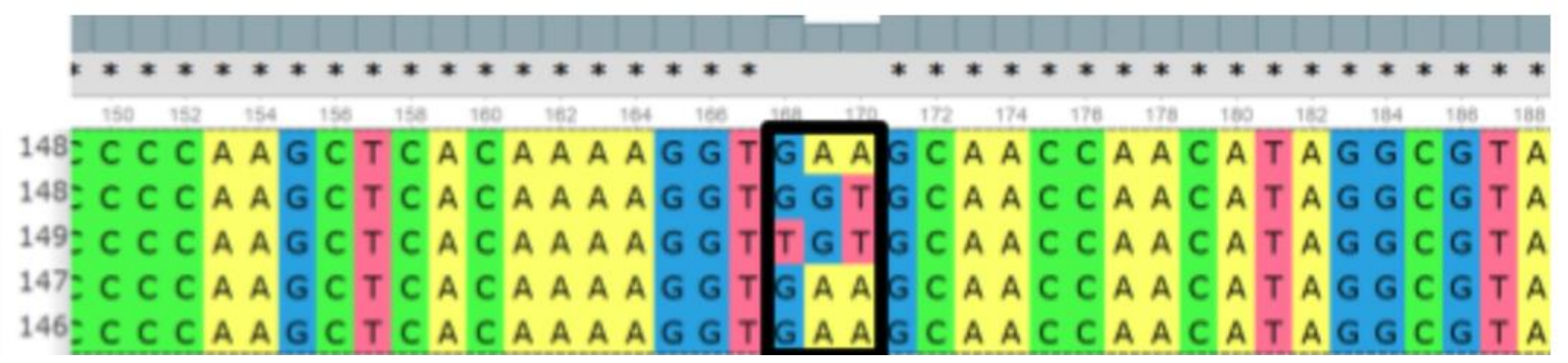

Figure 8: Sequences of PCR products from colonies from the first HiFi assembly. The boxed area is the location of the E66 codon. Out of the 5 colonies analyzed, 3 contained 
the wild-type GAA codon, and 2 mutant codons were found: glycine, GGT and cysteine UGU. Sequences were analyzed and visualized in UGene.

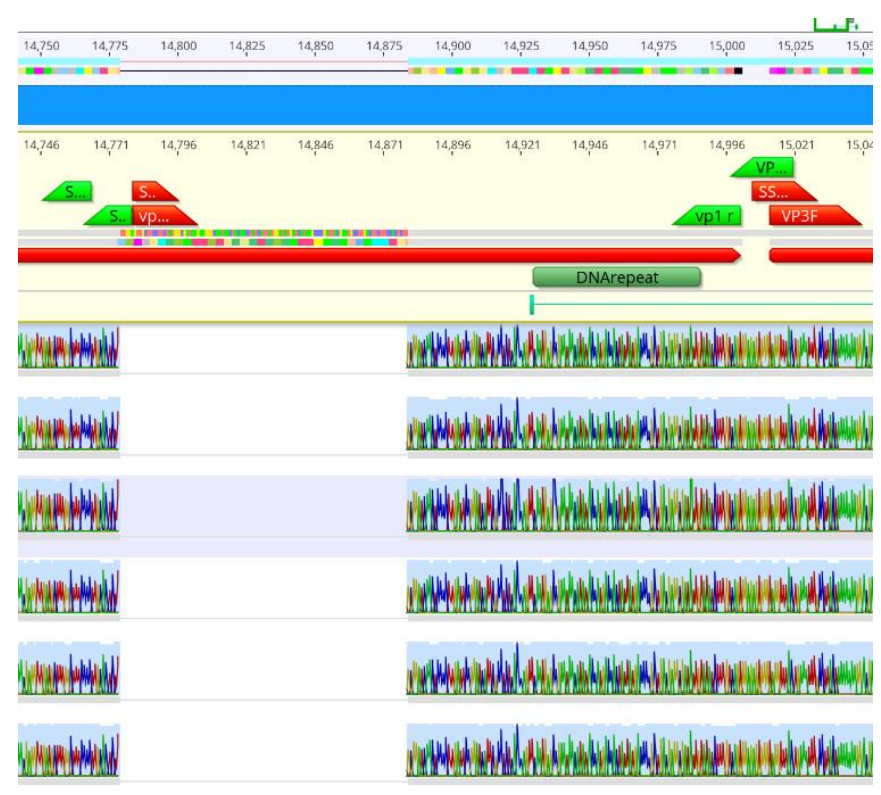

Figure 9: Sequence chromatograms from the second round of HiFi Assembly that resulted in deletions. Sequences were aligned with the SSV1 wild-type region of VP1. The area where the E66 codon should have been is missing. Out of the 6 colonies sequenced all contained the deletion mutation. 


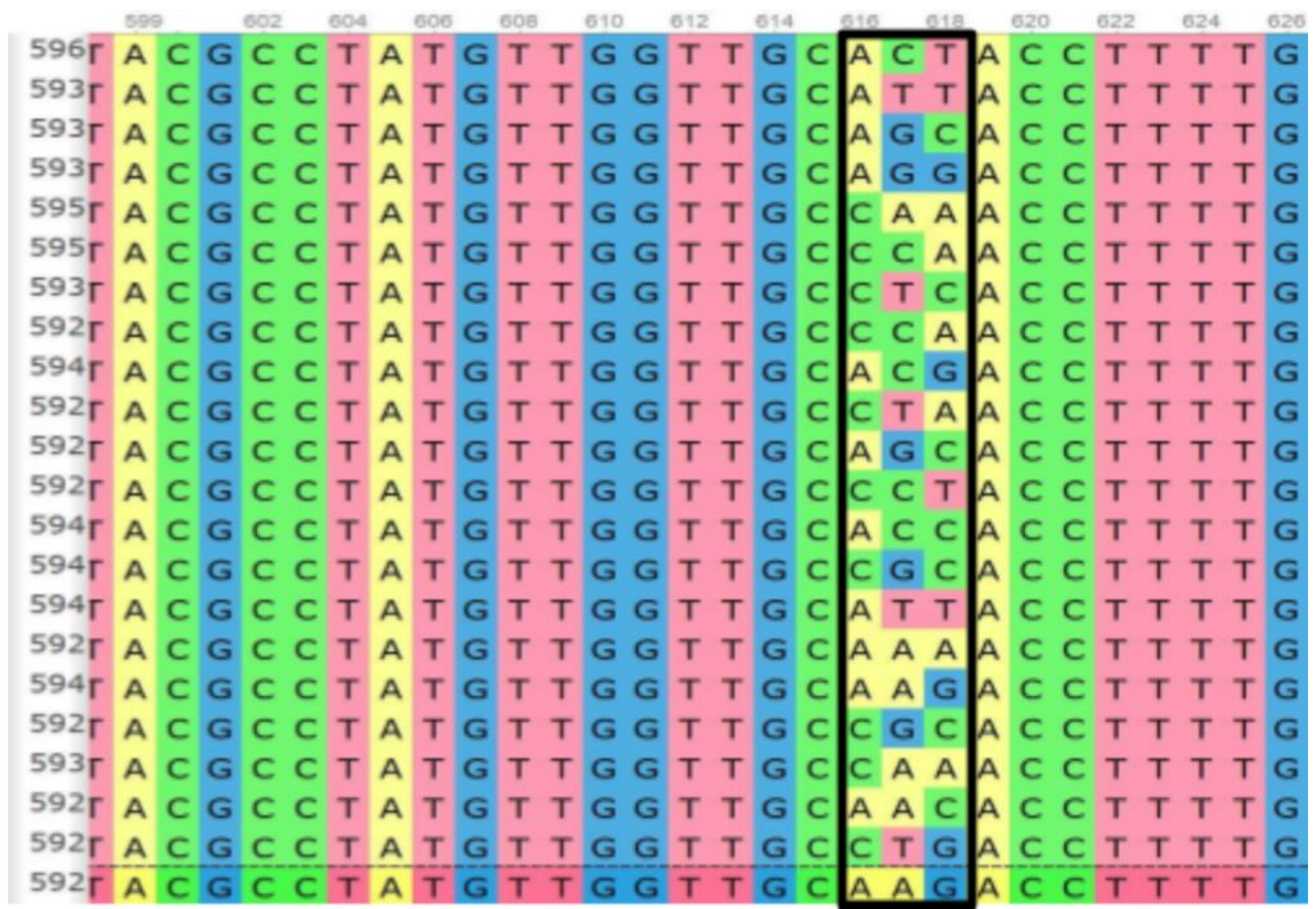

Figure 10: Sequences of PCR products from colonies from the third HiFi assembly. The boxed area is the location of the E66 codon. Out of the all colonies analyzed, all were mutant codons. Sequences analyzed and visualized in UGene. 


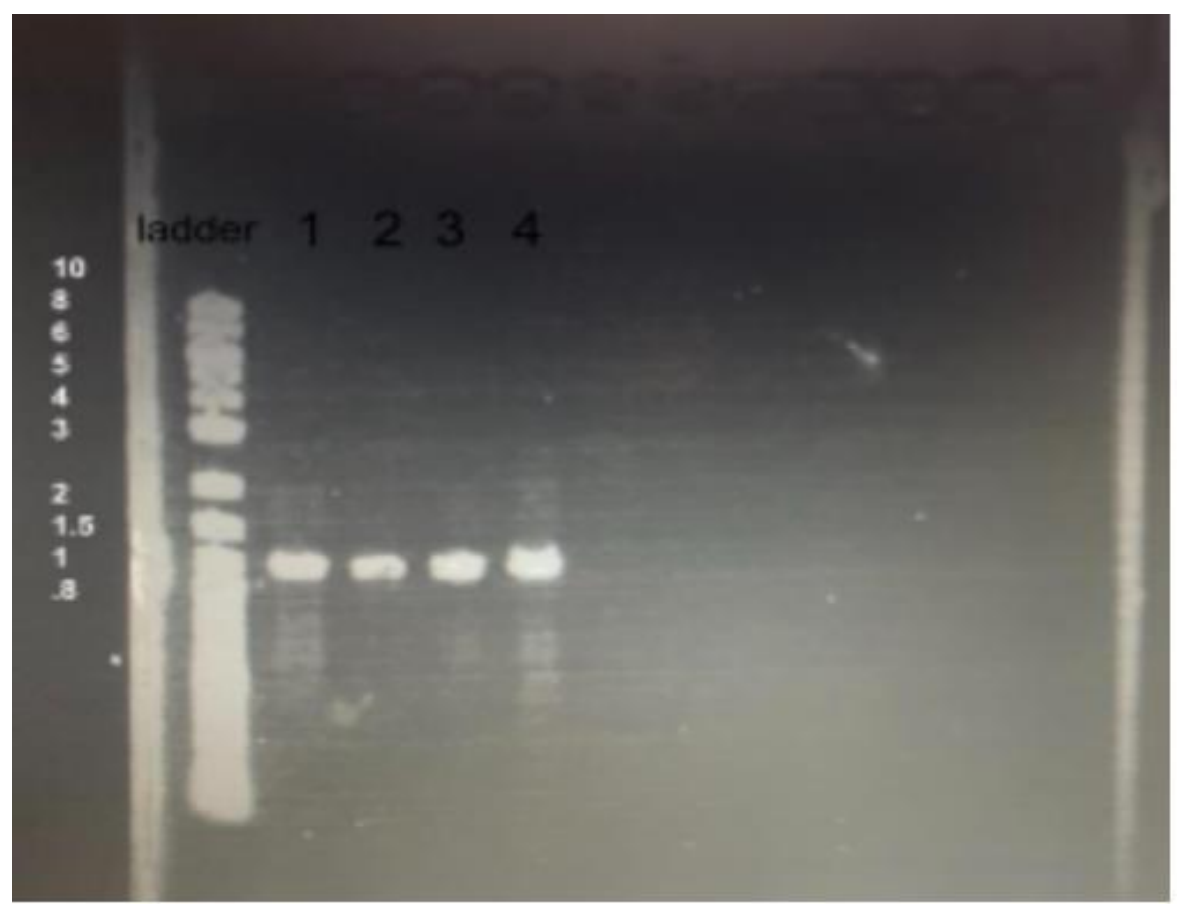

Figure 11: 1\% Agarose gel electrophoresis of representative products from the assembly confirmation PCR reaction used to confirm the proper orientation of the DNA fragments. Ladder, $1 \mathrm{~Kb}$ plus (NEB) with sizes labeled; Lane 1, mutant 4S; Lane 2, mutant 4F; Lane 3, mutant 3B; Lane 4, mutant 4J.

Table 3: All mutants at their codon level and corresponding amino acid 


\begin{tabular}{|c|c|c|}
\hline Amino Acid & Codon & Name of Mutants \\
\hline Phe & UUU & $4 \mathrm{~A}, 5 \mathrm{C}, 3 \mathrm{E}$ \\
\hline \multirow[t]{2}{*}{ Leu } & CUU & $5 \mathrm{Q}, 4 \mathrm{~N}$ \\
\hline & UUG & $3 \mathrm{I}, 6 \mathrm{C}, 5 \mathrm{~K}, 6 \mathrm{E}$ \\
\hline lle & AUU & $4 \mathrm{P}, 4 \mathrm{~W}, 4 \mathrm{O}$ \\
\hline Methionine & AUG & Fresh Met \\
\hline \multirow[t]{2}{*}{ Ser } & AGU & $4 \mathrm{~L}, 3 \mathrm{C}$ \\
\hline & UCU & $4 G$ \\
\hline \multirow[t]{2}{*}{ Pro } & $\mathrm{CCU}$ & $3 \mathrm{~J}, 5 \mathrm{~F}$ \\
\hline & CCG & $5 W$ \\
\hline \multirow[t]{2}{*}{ Thr } & $\mathrm{ACU}$ & $3 \mathrm{D}, 3 \mathrm{~A}$ \\
\hline & ACG & $3 B$ \\
\hline Gln & CAG & $5 U, 4 S$ \\
\hline Asn & AAU & $4 C, 5 D$ \\
\hline Lys & AAG & $4 \mathrm{~F}$ \\
\hline \multirow[t]{2}{*}{ Glu } & GAA & Wild Type, 6D, B \\
\hline & GAG & $3 G$ \\
\hline Cys & UGU & $5 G, D$ \\
\hline \multirow[t]{2}{*}{ Arg } & AGC & $5 \mathrm{~J}$ \\
\hline & CGT & $4 \mathrm{X}, 4 \mathrm{~N}$ \\
\hline Gly & GGU & $6 \mathrm{~A}, 4 \mathrm{~J}, \mathrm{C}, 5 \mathrm{I}$ \\
\hline \multirow[t]{2}{*}{ Ala } & GCT & $4 \mathrm{~B}, 5 \mathrm{~A}, 6 \mathrm{~B}$ \\
\hline & GCG & $5 \mathrm{~L}, 5 \mathrm{E}$ \\
\hline STOP & TAG & $5 B$ \\
\hline Val & GUU & $5 Y$ \\
\hline Trp & UGG & $3 \mathrm{~F}, 3 \mathrm{H}$ \\
\hline
\end{tabular}

Missing Aspartic acid, Histidine, Asparagine, Tyrosine

Once the presence of the mutation was confirmed, the vectors were purified from E.coli using NEB's miniprep kit. To confirm that all three fragments were assembled in the right orientation, PCR or restriction endonuclease analysis via Xmal or Ncol (data not shown) was conducted (Figure 11). The purified vector encoding each of the mutant 
viruses was electroporated into SSV1's host Saccharolobus solfataricus (S441 strain). The electroporated host cells were grown in a nutrient rich broth, YS Media, in a shaking incubator for $2-5$ days at $78-80^{\circ} \mathrm{C}$. After this time, a supernatant PCR was conducted to test for the presence of viral DNA in the media. Ten of the mutant vectors were electroporated into S441. Supernatant PCR was positive after two electroporations (Figure 12). These were followed by sequencing to confirm the identity of the viral mutants. These corresponded to a methionine mutant and glutamine mutant, 4S (data not shown), with a different codon than a previous mutant E66Q (Iverson et al. 2017b).
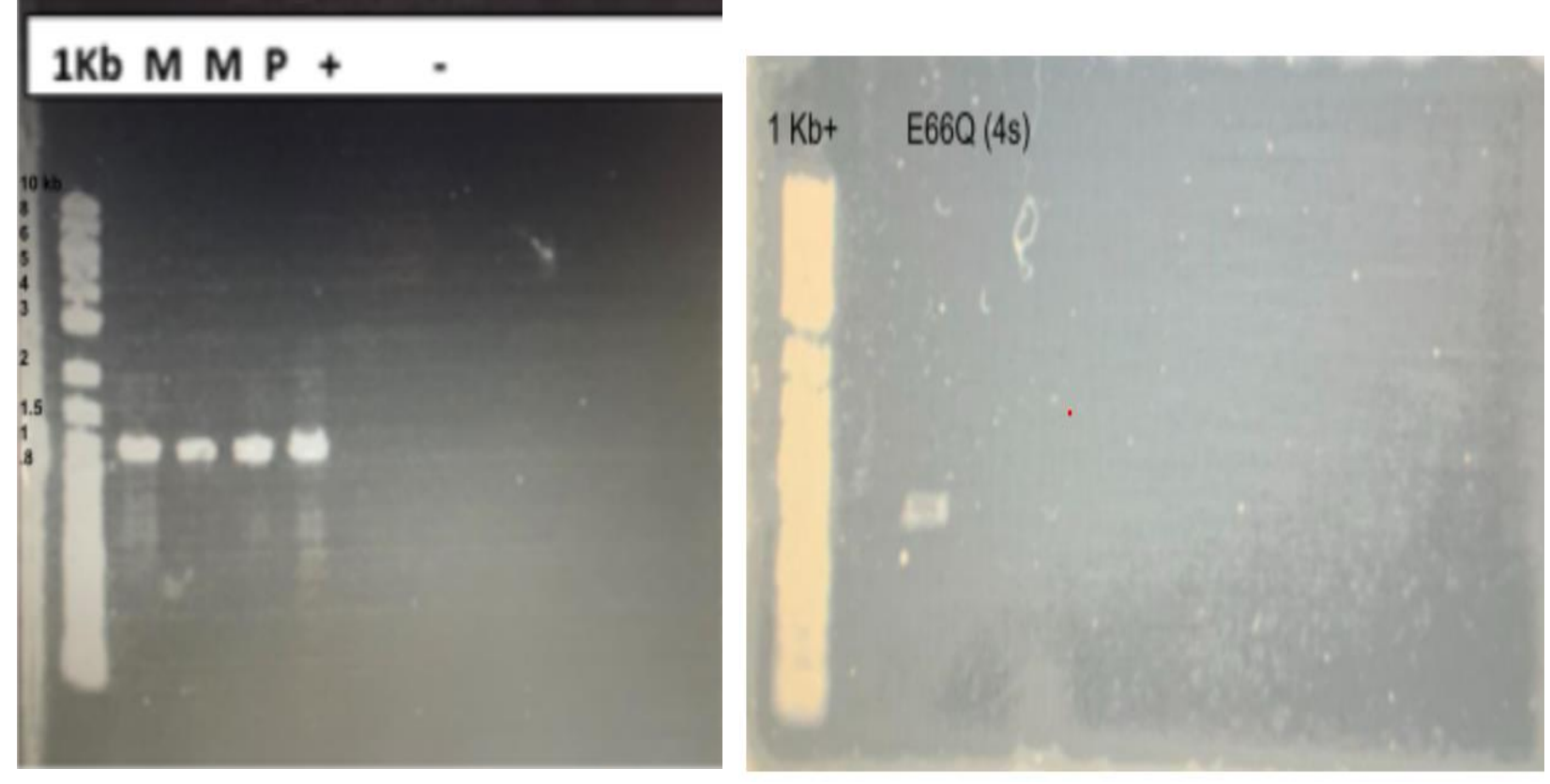

Figure 12: Left: $1 \%$ Agarose gel electrophoresis of PCR products amplified from electroporated culture for methionine (labeled ' $M$ '), with ' $P$ ' being the positive control for the electroporation and the ' + ' the positive control for the PCR. Right: Agarose gel electrophoresis of the product of the supernatant PCR for E66Q(4S) mutant.

Virions from supernatants of Saccarolobus solfataricus cultures electroporated with SSV1 mutants were concentrated by centrifugation in $6 \mathrm{~mL}$ VivaSpin concentrator tubes. The concentrated virions were prepared for transmission electron microscopy using a copper grid and uranyl acetate for staining. Virions from two mutants, methionine and glutamine, were viewed successfully with the transmission electron microscope (Figure 13). 

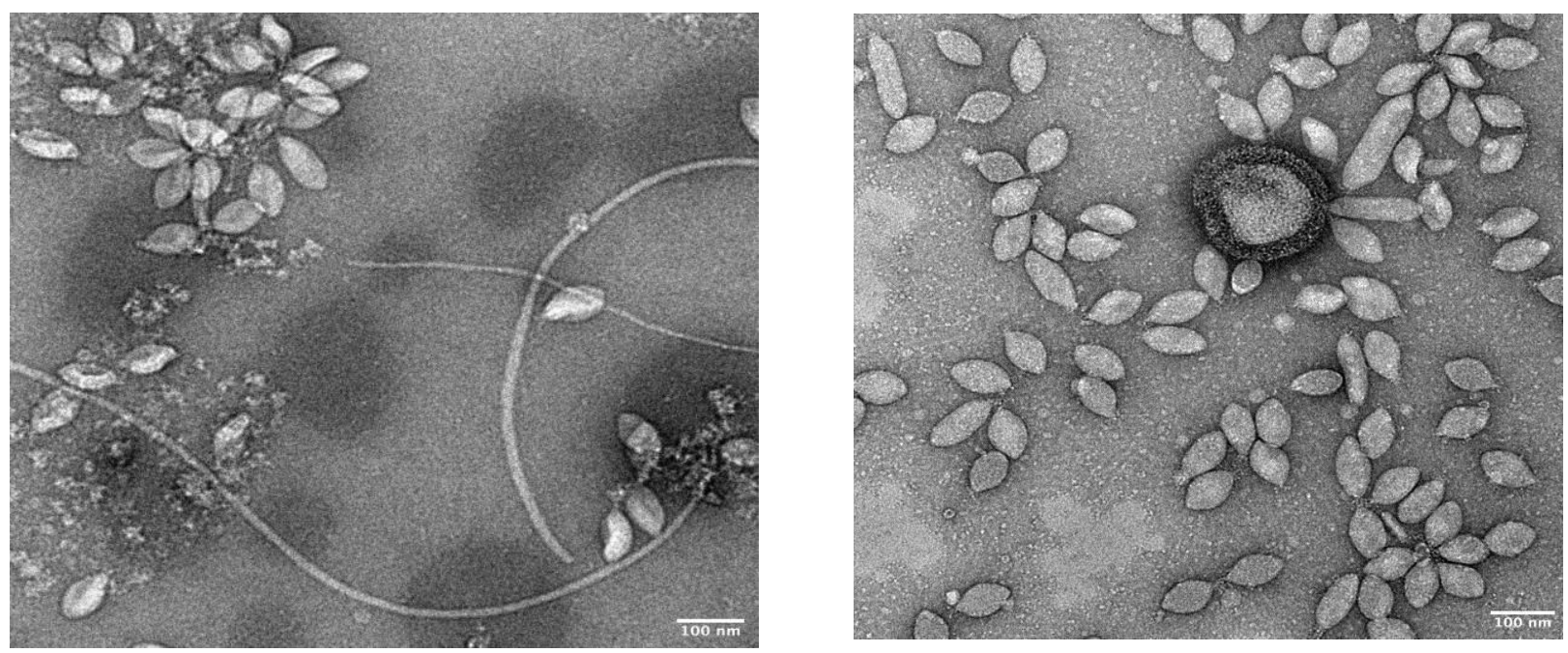

Figure 13: Transmission electron microscope (TEM) images for the mutants E66M (left) E66Q (right).

Next, halo assays for growth inhibition of uninfected strains were performed to test the infectivity of the mutants. There were two problems encountered when attempting halo assays. The first being the uninfected lawn of the host was not growing. A PCR of the S441 stocks showed that there was contamination from wild-type SSV1. After switching to new uninfected stocks, successful lawns were grown. The second issue encountered was that the plates were melting in the $80^{\circ} \mathrm{C}$ incubator. An experiment was conducted with varying thicknesses of the hard $\mathrm{YS}$ layer and was incubated at $80^{\circ} \mathrm{C}$. It was shown that plates with lower thickness melt and plates with at least $25 \mathrm{~mL}$ of solution for the hard layer were able to maintain the structure at higher temperatures. To further test the plates for their ability to grow, different Saccarolobus strain samples were spotted on plates and incubated for $2-3$ days at $70^{\circ} \mathrm{C}$, and growth was observed (not shown).

To increase the reproducibility of the lawns more testing was completed. From testing, it was discovered that the $S 441$ cultures of about $7 \mathrm{~mL}$ needed to be grown to an optical density (OD) of 0.6 . Then the culture had to be centrifuged at $3,260 \times \mathrm{g}$ for about $15-20 \mathrm{~min}$. The supernatant was decanted, and the pellet resuspended in $0.5 \mathrm{~mL}$ of YS. To make the soft layer only $3 \mathrm{ml}$ of the YS/Gelrite solution was necessary and once poured should be laid to rest on a leveled surface until the soft layer has hardened and cooled to room temperature for about $20 \mathrm{~min}$. We also noticed that the soft layer should remain leveled in the incubator. These measures have allowed for successful lawns and halo assays. After the optimization of the lawns and plates using thicker plates and new stocks of $\$ 441$ there was successful growth of lawns and a successful halo assay for the E66Q mutant (Figure 14). 


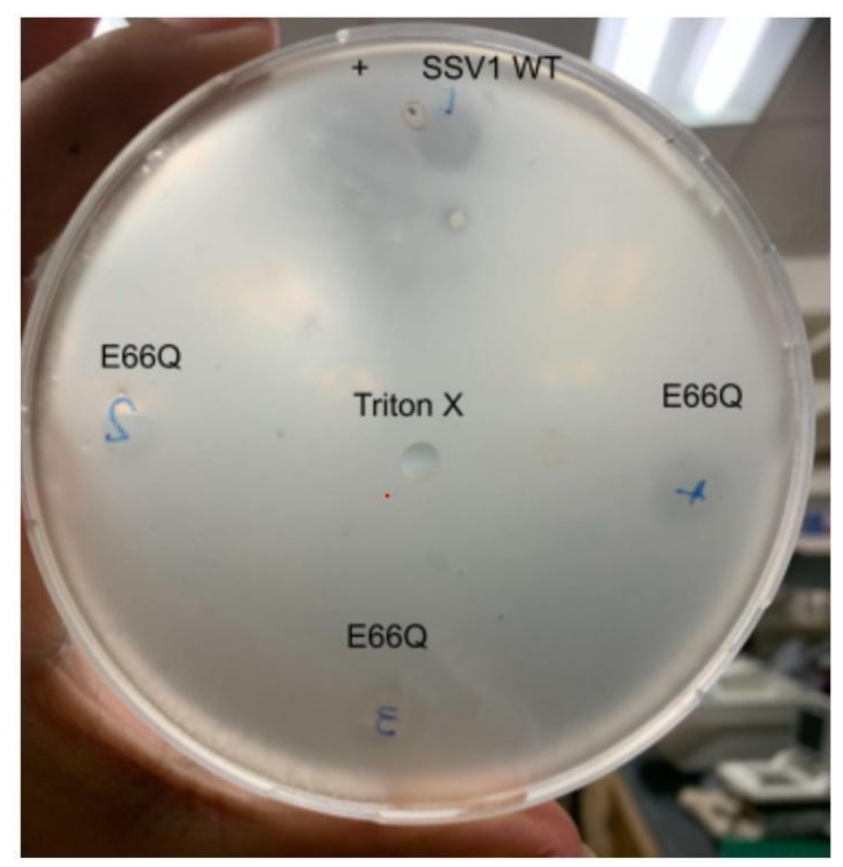

Figure 14: A halo assay of E66Q mutant. The halos are the clearings found in the spotted areas of the lawn. (1) Wild-type SSV1 in host (2-4) are E66Q mutants spotted at three different locations. The E66 mutants and the positive control resulted in halos.

\section{Discussion}

The goal of the study was to develop a process for efficiently producing many point mutants in SSV1's major capsid protein (VP1) by changing the Glutamic acid at the VP1 cleavage site, position 66, to the remaining 19 amino acids. Previously, LIPCR was used to produce point mutations; however, optimization of this process could take weeks to months per mutant (Iverson et al. 2017b). So, LIPCR would not be a cost- or time-effective manner to produce the 19 mutants at the E66 position. Through optimization of the HiFi Assembly process using a degenerate oligonucleotide, many different mutants were produced in one reaction (Figure 10). Mutagenic cloning through HiFi Assembly has allowed the production of 16 distinct amino acid substitutions. Most mutants were produced in one assembly reaction (Figure 10), which demonstrated that this methodology can be successfully used to introduce point mutations on a large scale. However, due to the degeneracy of the genetic code, multiple repeated amino substitutions were found (Table 3). From the mutants that we screened, the rarer codons - like methionine and histidine- were not found in the 50 colonies that have been sequenced. Thus, we opted to use specific mutagenic primers for generating the methionine substitution. This was done by designing PCR primers so that the fragments assembled contained the mutant rather than a bridging mutagenic oligonucleotide.

To optimize the assembly reaction of the mutagenic EAl283 vectors, there were three separate attempts at the HiFi Assembly cloning. The first round of HiFi Assembly 
produced about $60 \%$ wild-type mutants (Figure 8 ). We hypothesized that this was a result of the original PCR DNA templates serving as a substrate for the assembly process for the HiFi enzymes. Therefore, in the next round, the DNA template was removed with a treatment of Dpnl followed by purification of PCR products using the NEB Monarch PCR and DNA cleanup kit to prevent the template from serving as a fragment for HiFi assembly. However, in the second reaction, in trying to maximize the yield of mutants, the concentration of each fragment totaled over 0.2 picomoles. This seems to have prevented the fragments from combining as expected, as there were more PCR fragments 1 and 2 relative to the oligonucleotide bridge. In this case, the assembly reaction resulted in a deletion mutation probably due to a small region of sequence identity in VP1 on either side of the overlapping DNA (Figure 9). To ensure that this deletion does not occur, the total DNA concentration of all the fragments was kept below 0.2 picomoles, as recommended by the HiFi kit protocol. Thus, for the third round of HiFi Assembly, the DNA was treated with Dpnl and the assembly reaction had a greater relative concentration of mutagenic oligonucleotide to fragments 1 and 2 . This reaction was more successful, as the screening showed that each colony tested resulted in a mutant (Figure 10). Thus, care needs to be taken to ensure that the total DNA in the HiFi reaction lies below 0.2 picomoles of total DNA, regardless of fragment size or length. This may minimize the rearranging of fragments or non-specific interactions.

In future endeavors to fine-tune the protocol, we will try to optimize the reaction to minimize the number of identical mutants that were created through this procedure. Certain codons appeared at a higher frequency than others (Table 3). This might be due to the transformation procedure that allows the cells to grow for 30 minutes before they are plated, which is enough time for the E.coli to reproduce, possibly resulting in multiple colonies containing identical clones. This could be evaluated in the future.

After the confirmed mutant vectors had been electroporated into the uninfected host, S441, and grown in a liquid culture for $2-5$ days, a supernatant PCR was performed to test for the presence of viral material in the liquid media presumably due to the presence of virions in the supernatant. Supernatant PCR of the positive control, in a successful electroporation, showed amplification while the negative control did not. The PCR does not screen for the mutant but rather just the presence of the viral DNA. The PCR product was sequenced to confirm the presence of the mutation. Two successful electroporations were completed for methionine and glutamic acid mutants (Figure 12).

After confirming the presence of the mutation, infectivity was confirmed using a halo assay by spotting $5 \mu \mathrm{l}$ of infected culture on the lawn of an uninfected host and observing the effects to see if a halo of growth inhibition forms around the spot. Initial attempts to produce halos were not successful. Since there is a positive supernatant PCR results, we expect to confirm infectivity with halos. However, it is possible that mutants will not form halos but can still be infectious.

Through the optimization, increased thickness of the plates and the concentration of the uninfected cells, successful halo assays were conducted on the E66Q mutant that 
produced clearings in the lawn, as seen in Figure 14. The production of halos and positive supernatant PCR indicated that the E66Q mutant is infectious and that the mutation does result in viable viruses, which confirms the results from the previous E66Q mutant with a different codon (Iverson et al. 2017b). Moving forward, the goal is to reproduce this entire process for all the E66 mutants and to test what mutations result in viable viruses.

Another area of interest is the structure of these viable viruses, so transmission electron microscope (TEM) images were captured for each of these mutant virions once their presence was confirmed by supernatant PCR. $50 \mathrm{~mL}$ culture supernatants were concentrated and stained with uranyl acetate. Figure 13 shows virions of the two mutant viruses by TEM imaging, further confirming the viability of these mutants. The E66Q mutant has a more heterogeneous virion structure with some being cylindrical or larger than the typical wild-type of spindle shaped virion, which is similar to the results shown from the initial experiment with a glutamine mutant with a different codon sequence (Iverson et al. 2017b). The E66M mutants displayed the characteristic wild-type spindle shaped virions (Stedman et al. 1999) that didn't have any heterogeneous virion structures. This could be because methionine is a start codon amino acid, and VP1 could act like a cleaved protein if this methionine serves as an alternative start codon. In the future, the structure of other successful mutant viruses will be tested and imaged using the TEM.

\section{Acknowledgements}

I would like to acknowledge those who helped me throughout this process: Dr. Kenneth Stedman for support and guidance, Dr. Ignacio de la Higuera for his support and guidance, Deniz Erkok for the work on the Methionine mutant, Jennie Tran and Jono Abshier for their support and involvement throughout the process. I also would like to thank BUILD EXITO program, Lester Newman undergraduate research scholarship, and the Portland State REU program for their funding. 


\section{References}

1. Brock, Thomas D., et al. "Sulfolobus: a new genus of sulfur-oxidizing bacteria living at low pH and high temperature." Archiv für Mikrobiologie 84.1 (1972): 5468.

2. Clore, Adam J, and Kenneth M Stedman. "The SSV1 Viral Integrase Is Not Essential." Virology (New York, N.Y.), vol. 361, no. 1, 2006, pp. 103-111.

3. Iverson, Eric, and Kenneth Stedman. "A Genetic Study of SSV1, the Prototypical Fusellovirus." Frontiers in Microbiology, vol. 3, 2012, p. 200.

4. Iverson, Eric A, et al. "Extreme Mutation Tolerance: Nearly Half of the Archaeal Fusellovirus Sulfolobus Spindle-Shaped Virus 1 Genes Are Not Required for Virus Function, Including the Minor Capsid Protein Gene vp3." Journal of Virology, vol. 91, no. 10, 2017a, pp. Journal of virology, 2017-05-15, Vol.91 (10)

5. Iverson, Eric A, et al. "Genetic Analysis of the Major Capsid Protein of the Archaeal Fusellovirus SSV1: Mutational Flexibility and Conformational Change." Genes, vol. 8, no. 12, 2017b, p. 373.

6. Martin, Andrea, et al. "SAV 1, a Temperate U.v.-Inducible DNA Virus-like Particle from the Archaebacterium Sulfolobus Acidocaldarius Isolate B12." The EMBO Journal, vol. 3, no. 9, 1984, pp. 2165-2168.

7. Krupovic, Mart, et al. "Unification of the Globally Distributed Spindle-Shaped Viruses of the Archaea." Journal of Virology, vol. 88, no. 4, 2014, pp. 2354-2358.

8. Prangishvili, David. "The Wonderful World of Archaeal Viruses." Annual Review of Microbiology, vol. 67, no. 1, 2013, pp. 565-585.

9. Quemin, Emmanuelle R. J, et al. "Sulfolobus Spindle-Shaped Virus 1 Contains Glycosylated Capsid Proteins, a Cellular Chromatin Protein, and Host-Derived Lipids." Journal of Virology, vol. 89, no. 22, 2015, pp. 11681-11691.

10. Rice, G, et al. "Viruses from Extreme Thermal Environments." Proceedings of the National Academy of Sciences - PNAS, vol. 98, no. 23, 2001, pp. 13341-13345.

11. Reiter, Wolf-Dieter, et al. "Identification and characterization of the genes encoding three structural proteins of the Sulfolobus virus-like particle SSV1." Molecular and General Genetics MGG 206.1 (1987): 144-153.

12. Sakai, Hiroyuki D., and Norio Kurosawa. "Saccharolobus caldissimus gen. nov., sp. nov., a facultatively anaerobic iron-reducing hyperthermophilic archaeon isolated from an acidic terrestrial hot spring, and reclassification of Sulfolobus solfataricus as Saccharolobus solfataricus comb. nov. and Sulfolobus shibatae as Saccharolobus shibatae comb. nov." International journal of systematic and evolutionary microbiology 68.4 (2018): 1271-1278.

13. Sambrook, Joseph, and David W. Russell. "Preparation and transformation of competent E. coli using calcium chloride." Cold Spring Harbor Protocols 2006.1 (2006): pdb-prot3932. 
14. Stedman, Kenneth $M$, et al. "Genetic Requirements for the Function of the Archaeal Virus SSV1 in Sulfolobus Solfataricus: Construction and Testing of Viral Shuttle Vectors." Genetics (Austin), vol. 152, no. 4, 1999, pp. 1397-1405.

15. Stedman, Kenneth M, et al. "Relationships between Fuselloviruses Infecting the Extremely Thermophilic Archaeon Sulfolobus: SSV1 and SSV2." Research in Microbiology, vol. 154, no. 4, 2003, pp. 295-302.

16. Stedman, Kenneth $M$, et al. "Structural Insights into the Architecture of the Hyperthermophilic Fusellovirus SSV1." Virology (New York, N.Y.), vol. 474, 2015, pp. 105-109.

17. Sultan, I. N., et al. "Formulation of an Efficient Combinatorial Cellulase Cocktail by Comparative Analysis of Gibson Assembly and NEBuilder HiFi DNA Assembly Modus Operandi." (2020).

18. Yeats, Siobhán, et al. "A Plasmid in the Archaebacterium Sulfolobus Acidocaldarius." The EMBO Journal, vol. 1, no. 9, 1982, pp. 1035-1038. 